\author{
UNIVERSIDADE DE SÃO PAULO \\ FACULDADE DE MEDICINA DE RIBEIRÃO PRETO
}

MARINA GONZALEZ RIBAS

Efeito do diazepam em facilitar a colocação dos dispositivos durante procedimento de esterilização tubária por histeroscopia: estudo clínico randomizado e controlado 


\section{Efeito do diazepam em facilitar a colocação dos dispositivos durante procedimento de esterilização tubária por histeroscopia: estudo clinico randomizado e controlado}

Dissertação apresentada à Faculdade de Medicina de Ribeirão Preto da Universidade de São Paulo para obtenção do Título de Mestre em Ciências.

Área de Concentração: Tocoginecologia

Orientador: Prof. Dr. Júlio César Rosa e Silva 
AUTORIZO A REPRODUÇÃO E DIVULGAÇÃO TOTAL OU PARCIAL DESTE TRABALHO, POR QUALQUER MEIO CONVENCIONAL OU ELETRÔNICO, PARA FINS DE ESTUDO E PESQUISA, DESDE QUE CITADA A FONTE.

FICHA CATALOGRÁFICA

Ribas, Marina Gonzalez

Efeito do diazepam em facilitar a colocação dos dispositivos durante procedimento de esterilização tubária por histeroscopia: estudo clínico randomizado e controlado. / Marina Gonzalez Ribas; Orientador, Júlio César Rosa e Silva. Ribeirão Preto. - 2019.

60p.: 1 il.; $30 \mathrm{~cm}$

Dissertação (Mestrado) - Programa de Ginecologia e Obstetrícia. Área de Concentração: Tocoginecologia. Faculdade de Medicina de Ribeirão Preto da Universidade de São Paulo, Ribeirão Preto, 2019.

1. Esterilização tubária. 2. Diazepam. 3. Placebo. 4. Facilitar. 5. Inserção. 6. Histeroscopia. 


\section{FOLHA DE APROVAÇÃO}

Aluno: Ribas, Marina Gonzalez

Título: Efeito do diazepam em facilitar a colocação dos dispositivos durante procedimento de esterilização tubária por histeroscopia: estudo clínico randomizado e controlado.

Dissertação apresentada à Faculdade de Medicina de Ribeirão Preto da Universidade de São Paulo para obtenção do Título de Mestre em Ciências.

Área de Concentração: Tocoginecologia.

Aprovado em:

Prof. Dr.

Instituição:

Assinatura:

Prof. Dr.

Instituição:

Assinatura:

Prof. Dr.

Instituição:

Assinatura:

Prof. Dr.

Instituição:

Assinatura: 


\section{Dedicatória}

Aos meus pais Therezinha e Durval por ter a honra de conviver com dois exemplos de médicos humanos, dedicados e sempre em busca do melhor conhecimento para com os pacientes e por isso tendo me apoiado e incentivado tanto nessa jornada.

Ao meu esposo Rafael, meu companheiro em todas as horas, pela paciência e apoio incondicional a todos os meus sonhos.

Ao meu irmão Durval Neto, por me apoiar e desejar sempre meu sucesso.

À minha filha Celina, ainda recém-nascida, mas que espero ser inspiração para seus passos em busca de conhecimento. 


\section{Agradecimento Especial}

Ao meu orientador Prof. Dr. Júlio César Rosa e Silva, um grande professor e orientador, sempre buscando me ajudar com toda sua paciência e honestidade. Também pelo seu bom senso em querer o melhor para as pacientes mantendo acima de tudo os principios éticos. 


\section{Agradecimentos}

A toda minha familia, que sempre me apoiou e manifestou palavras de ânimo.

Ao Departamento de Ginecologia e Obstetrícia da Faculdade de Medicina de Ribeirão Preto da Universidade de São Paulo, que permitiu realizar e concluir este projeto.

À Comissão Coordenadora do Programa de Pós-graduação em Ginecologia e Obstetrícia, da Faculdade de Medicina de Ribeirão Preto da Universidade de São Paulo, pelo apoio e incentivo em tantas ocasiões e a todos que compõem o Departamento de Ginecologia e Obstetrícia da Faculdade de Ribeirão Preto, pelo contínuo aprendizado, indispensável à minha formação profissional.

Aos funcionários Sr. Reinaldo Tavares, Sra. Rosane Casula, Sra. Gabriela Francisco Sicca e Srta. Suelen Soares, incansáveis colaboradores de minha jornada.

Aos Professores Drs. Omero Benedicto Poli-Neto, Antônio Alberto Nogueira, Francisco José Candido dos Reis pelos inestimáveis conselhos, pelas correções e coorientações.

À Dra. Ana Carolina Tagliatti Zani, médica assistente e amiga, que além de ter participado diretamente do estudo, me ajudou muito com sua experiência, seu conhecimento e bom senso.

À Sra. Suleimy Cristina Mazin, que me ajudou muito com as análises estatísticas do estudo, teve paciência e dedicação quando mais precisei. 
A todos os funcionários do Setor de Endoscopia do Hospital das Clínicas da Faculdade de Medicina de Ribeirão Preto da Universidade de São Paulo, em especial a Sra. Graciana Dutra de Castro, pelo tempo que se dedicou para a conclusão do meu projeto.

Aos amigos do Setor de Vídeo-endoscopia Ginecológica do Hospital das Clínicas da Faculdade de Medicina de Ribeirão Preto da Universidade de São Paulo, pelo prazer de ter convivido com vocês, dentro e fora do trabalho durante o ano de residência.

A todos que, direta ou indiretamente, contribuíram para realização deste estudo. 
Ribas MG. Efeito do diazepam em facilitar a colocação dos dispositivos durante procedimento de esterilização tubária por histeroscopia: estudo clínico randomizado e controlado. Dissertação (Mestrado) - Faculdade de Medicina de Ribeirão Preto, Universidade de São Paulo. Ribeirão Preto. 2019.

Vários fatores são apontados para predizer a taxa de sucesso na colocação dos dispositivos tubários na esterilização por histeroscopia, sendo um deles o uso de medicamentos antes do procedimento como os anti-inflamatórios não esteroidais (AINEs), os mais avaliados quanto à facilidade na colocação dos dispositivos nas tubas, e o diazepam, um ansiolítico que atua na redução da ansiedade das pacientes e na motilidade tubária. Ambos são recomendados pelo fabricante, mas não há uma avaliação do diazepam quanto a sua possível relação com o relaxamento tubário no intuito de diminuir seu vasoespasmo aumentando a taxa de sucesso do método ou de critérios específicos para ser adotado como rotina. $O$ objetivo desse estudo foi avaliar o efeito da dose de $10 \mathrm{mg}$ de diazepam via oral previamente ao procedimento de esterilização tubária histeroscópica facilitando a inserção dos dispositivos no interior das tubas. Para isso, foram inseridas 82 pacientes que escolheram a esterilização tubária histeroscópica como método anticoncepcional e randomizadas em dois grupos, sendo 43 que tomaram $10 \mathrm{mg}$ de diazepam e 39 que tomaram medicação sem substância (placebo) trinta minutos antes do procedimento. Foi avaliada a facilidade de colocação dos dispositivos pelo médico que realizou o procedimento através da classificação do procedimento em fácil ou difícil aplicação. Em relação à facilidade na inserção do dispositivo, houve diferença estatística no lado direito que apresentou maior facilidade no grupo diazepam em relação ao placebo. Foi concluído que o uso do diazepam prévio na dose de $10 \mathrm{mg}$ e quando administrado 30 minutos previamente a esterilização tubária histeroscópica facilitou a colocação do dispositivo no lado direito, porém mais estudos deverão ser realizados para sua recomendação de rotina.

Palavras-chave: Esterilização tubária. Diazepam. Placebo. Facilitar. Inserção. Histeroscopia. 
Abstract 
Ribas MG. Effect of diazepam on facilitating the placement of devices during tubal sterilization procedure by hysteroscopy: a randomized controlled trial. Dissertação (Mestrado) - Faculdade de Medicina de Ribeirão Preto, Universidade de São Paulo. Ribeirão Preto. 2019.

Several factors are suggested to predict the success rate in the placement of tubal devices in tubal sterilization by hysteroscopy, one of which is the use of preprocedure medications such as nonsteroidal anti-inflammatory drugs (NSAIDs), which are the most evaluated for ease of device placement in the tubas and diazepam, an anxiolytic that works to reduce patient anxiety and tubal motility. Both are recommended by the manufacturer, but there is no evaluation of diazepam as to its possible relation to tubal relaxation in order to decrease its vasospasm by increasing the success rate of the method or specific criteria to be adopted as routine. The objective of this study was to evaluate the effect of the $10 \mathrm{mg}$ dose of oral diazepam prior to the hysteroscopic tubal sterilization procedure, facilitating the insertion of the devices into the tubas, and for this, 82 patients were chosen who chose hysteroscopic tubal sterilization as a contraceptive method and randomized in 2 groups, 43 of whom took $10 \mathrm{mg}$ of diazepam and 39 who took medication without substance (placebo) thirty minutes before the procedure. It was evaluated the ease of placement of the devices by the physician who performed the procedure through the classification of the procedure in easy or difficult application, as well as other quantitative and qualitative variables. Regarding the ease of insertion of the device, there was a statistical difference in the right side that presented greater ease in the diazepam group compared to placebo. It was concluded that the use of previous diazepam at the $10 \mathrm{mg}$ dose and when given 30 minutes prior hysteroscopic tubal sterilization seemed to facilitate the placement of the tubal sterilization device on the right side but further studies should be performed for its routine recommendation.

Key words: Tubal sterilization. Diazepam. Placebo. To facilitate. Insertion. Histeroscopy. 
Lista de Figuras 
Figura 1 - Escala de faces da International Association for the Study of

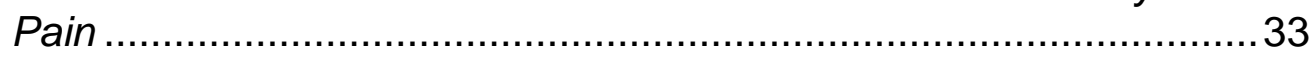


Lista de Tabelas 
Tabela 1 - Comparação das variáveis demográficas entre os dois grupos..............37

Tabela 2 - Comparação das inserções de cada óstio entre os dois grupos.............37

Tabela 3 - Concordância do resultado da inserção em cada óstio tubário ..............38

Tabela 4 - Comparação da dor e duração do procedimento entre os dois

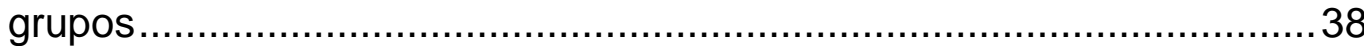

Tabela 5 - Comparação das queixas das pacientes entre os dois grupos após três meses do procedimento...................................................... 38

Tabela 6 - Concordância entre US 3D e Histerossalpingografia no óstio esquerdo após três meses do procedimento 39

Tabela 7 - Concordância entre US 3D e Histerosssalpingografia no óstio direito após três meses do procedimento 
Lista de Siglas, Simbolos e Abreviaturas 
$\%$

(

ABNT-

ACGC-

ACTZ-

AINEs-

BZNs-

cm

EVA-

FDA-

FMRP- USP- Faculdade de Medicina de Ribeirão Preto Universidade de São

g

HSG-

IASP-

IMC-

kg

$\mathbf{m}^{2}$

mg

US-

a

$\beta$ porcentagem

Marca Registrada

Associação Brasileira de Normas Técnicas

Ambulatório de Cirurgia Ginecológica

Ana Carolina Tagliatti Zani

Anti-inflamatórios não esteroidais

Benzodiazepínicos

centímetros

Escala Visual Analógica da Dor

Food and Drug Administration gramas

Histerossalpingografia

Escala de Faces da International Association for the Study of Pain

Índice de Massa Corporal

quilograma

metro ao quadrado

miligrama

Ultrassom

Alfa

Beta 


\section{SUMÁRIO}

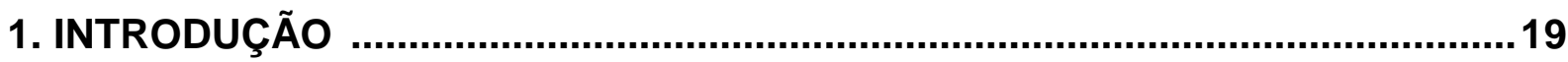

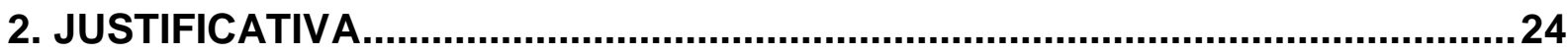

3. OBJETIVOS

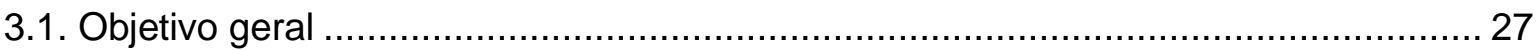

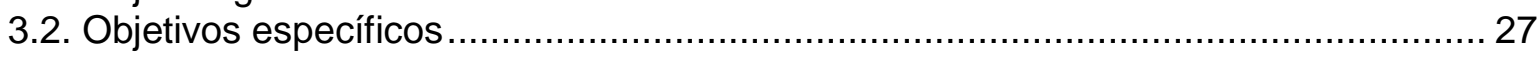

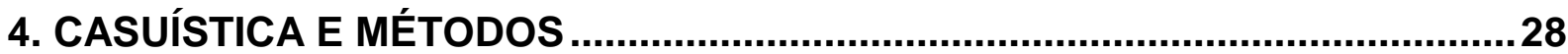

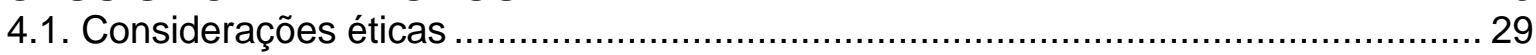

4.2. Tipo de estudo e local de desenvolvimento ......................................................... 29

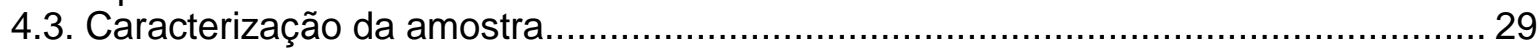

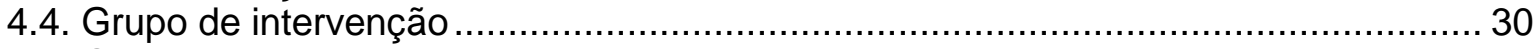

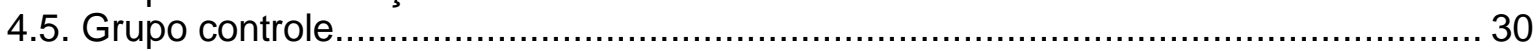

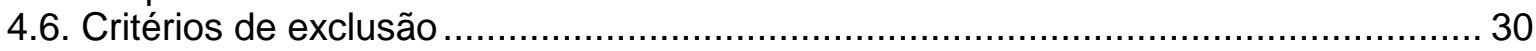

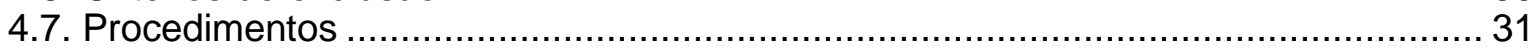

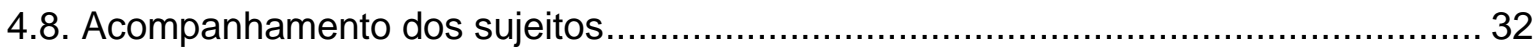

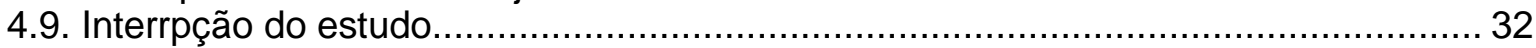

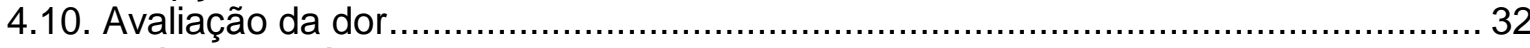

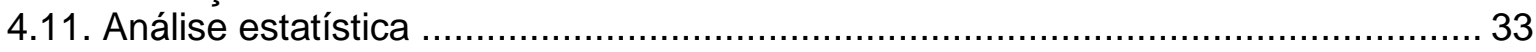

5. RESULTADOS

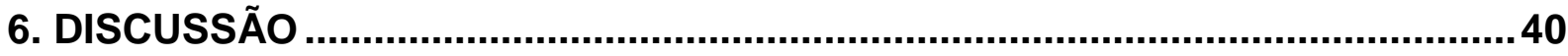

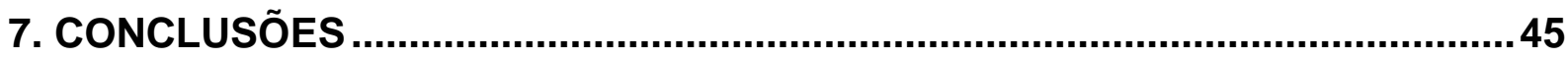

8. REFERÊNCIAS BIBLIOGRÁFICAS ............................................................ 47

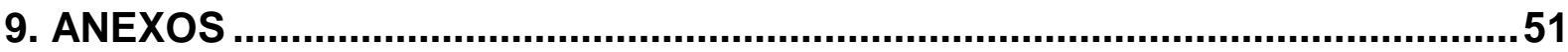


1- Introdução 
Apesar dos vários métodos contraceptivos disponíveis, a esterilização cirúrgica é considerada uma das mais populares, perdendo apenas para os contraceptivos orais como primeira escolha nos Estados Unidos (1). Em mulheres que desejam a contracepção definitiva, a esterilização é um método seguro e efetivo (1).

A laqueadura tubária é a mais utilizada dentre os métodos de esterilização cirúrgica, podendo ser realizada de várias maneiras (2). A laparoscopia é a técnica mais utilizada, podendo ser realizada através da ligadura tubária com anel ou clips, ablação com energia bipolar ou monopolar e até mesmo salpingectomia (2). Essas técnicas são acompanhadas de complicações associadas à anestesia geral, ou com lesões intestinais ou vasculares, que mesmo raras, podem ocorrer (1).

Mais recentemente, o desenvolvimento da esterilização pela via histeroscópica tornou possível a oclusão tubária irreversível sem abordagem abdominal com todas as suas implicações e até mesmo, muitas vezes, sem anestesia (3).

O primeiro esboço do que seria a esterilização tubária por histeroscopia surgiu na década de 1980, quando foi injetado silicone líquido através de um cateter no interior dos óstios tubários causando reação de fibrose após sua solidificação (4). Em 2002, o sistema de inserção Essure ${ }^{\circledR}$ foi aprovado, em que microdispositivos são colocados por histeroscopia na porção proximal das tubas, induzindo reação de fibrose, causando a oclusão tubária por volta de três meses após a inserção (5).

Os estudos têm demonstrado a efetividade e segurança desse procedimento, sendo que o sucesso na colocação dos dispositivos excede 95\% (6). Quando comparada com a laparoscopia, a técnica de esterilização por histeroscopia evitou gravidez mais eficazmente do que a laqueadura por laparoscopia (7). Em relação à segurança, os estudos demonstram baixas taxas de complicações. Franchini et al. (8) observaram em 1.913 pacientes submetidas à inserção dos dispositivos, que somente dez complicações foram relacionadas ao procedimento ou à inserção, sendo uma migração abdominal, cinco expulsões e quatro perfurações, das quais três assintomáticas (8). Em setembro de 2015, a Food and Drug Administration (FDA) debateu os eventos adversos relatados pelas pacientes em torno do 
dispositivo e concluiu não haver provas suficientes para remover o dispositivo do mercado (9).

Vários fatores são apontados para predizer a taxa de sucesso na colocação dos dispositivos, um deles é o uso de medicações previamente ao procedimento como anti-inflamatórios não-esteroidais (AINEs) que parecem facilitar sua colocação por meio da diminuição do vasoespasmo tubário (10). Já o diazepam, um benzodiazepínico que atua reduzindo a ansiedade das pacientes durante o exame, apesar de preconizado pelo fabricante, tem seu papel ainda incerto no relaxamento tubário. A tuba uterina é suprida por agentes parassimpáticos e simpáticos (11). As fibras pré-ganglionares do suprimento parassimpático se originam em segmentos espinhais S2 a S4 e atravessam os ramos do plexo esplâncnico pélvico para terminar nos gânglios próximos ao istmo tubário, aonde a inervação colinérgica pósganglionar ocorre (12). A ampola tubária recebe suprimento parassimpático dos ramos terminais do nervo vago, sendo a norepinefrina a principal catecolamina detectada. Já as fibras pré-ganglionares simpáticas dos segmentos vertebrais T12 para L2 ou L3 atravessam os ramos esplânicos lombares do tronco simpático e fazem sinapse com neurônios pós-ganglionares no plexo mesentérico inferior (13).

Existem dois tipos de receptores nas tubas uterinas: receptores Alfa ( $\alpha)$, que são geralmente estimulantes e os receptores Beta ( $\beta$ ), inibitórios (14). Esses receptores são subdivididos em $\beta 1$ e $\beta 2$, sendo o receptor $\beta 2$ predominante e estimulado, principalmente pela norepinefrina, responsável pelo relaxamento tubário (15). A concentração de norepinefrina é maior na região da ampola tubária. Esta região parece ser a responsável pelo mecanismo de relaxamento tubário, que é essencial para o processo normal de fertilização (16). Com base em flutuações nos níveis axonais do transmissor de norepinefrina, tem sido argumentado que a função dos neurônios adrenérgicos tubários varia em relação a diferentes fases do ciclo menstrual, inclusive com os níveis de estradiol e progesterona (17).

Já os benzodiazepínicos (BZNs) podem ser divididos em quatro grupos com base na sua estrutura, ou seja, se eles têm afinidade maior ou menor com o sítio de ligação de BZNs, de acordo com sua meia-vida, ou seja, maior ou menor que 12 horas. Os quatro grupos são as 2-ceto-benzodiazepinas, o 3-hidroxibenzodiazepinas, o triazolo-benzodiazepinas e as 7-nitro-benzodiazepinas (18). 0 
diazepam é o membro protótipo do grupo das 2-ceto-benzodiazepinas e são agentes de menor potência, porém têm meia-vida mais longa, em torno de 20-50 horas, porque passam por extensa biotransformação como pré-condição para sua eliminação do organismo (3). O diazepam é hidroxilado na posição 3; o metabólito resultante é o temazepam, que é desmetilado para formar oxazepam. Ambos os metabólitos são também comercializados como drogas ativas e são membros do próximo grupo, 3-hidroxi-benzodiazepinas (19).

O extenso metabolismo do diazepam é compartilhado por todos os membros do grupo 2-ceto e responde pela longa meia-vida. A meia-vida desses agentes também é encurtada ou prolongada pelo tratamento concomitante com indutores ou inibidores da enzima citocromo P450(CYP). Isso ocorre porque o metabolismo de drogas oxidativas se dá, principalmente na parede intestinal ou no fígado; e é principalmente mediada pelas enzimas CYP (20).

Os BZNs, como o diazepam, parecem apresentar efeito relaxante muscular, atribuído a uma ação modulatória dos receptores a1 adrenérgicos $(21,22)$. Esses dados experimentais permitem concluir que, além de sua ação central, essas drogas psicoativas possivelmente exerçam efeito tocolítico em adrenoreceptores alfa (23). O efeito relaxante no útero dos BZNs é pouco conhecido desde sua introdução em terapia, sugerindo um possível papel desta classe no tratamento de trabalho de parto prematuro (24). Essas drogas exercem ação uterotrópica direta, com um mecanismo mal compreendido. Como locais de ligação, os BZNs estão presentes no miométrio dos mamíferos, parecendo evidente que esses receptores periféricos são diretamente envolvidos no relaxamento uterino (25).

Zupkó et al. (26) (observaram tendência da propriedade antiadrenérgica dos BZNs em diminuir a atividade miometrial quando aplicados na gravidez. Foi avaliado o potencial tocolítico do diazepam, midazolam e nitrazepam in vivo em um modelo de rato pós-parto, juntamente com outros fármacos conhecidos por se ligarem a um adrenorreceptor. As interações de alguns deles, bem como da norepinefrina, também foram examinadas em um sistema in vitro isolado, sendo encontrada correlação entre o potencial tocolítico e constantes de inibição dos fármacos testados, sugerindo que o efeito relaxante muscular dessa classe é mediado pela modulação dos receptores a1-adrenérgicos. 
Com base nesses dados, este estudo visou avaliar o efeito do diazepam em facilitar a inserção dos dispositivos tubários no método de esterilização tubária por histeroscopia, a fim de analisar seu uso para este fim e trazer mais uma opção que poderia aumentar a taxa de sucesso de inserção desse tipo de método anticoncepcional. 
2. Justificativa 
Diante da falta de informações na literatura sobre o uso de diazepam prévio ao procedimento de laqueadura tubária por histeroscopia, o presente estudo visa avaliar esse efeito permitindo demonstrar se ele é benéfico não apenas em reduzir a ansiedade da paciente, mas também em facilitar a inserção dos dispositivos tubários e diminuir o tempo do procedimento e até mesmo a dor das pacientes que utilizam a medicação. 
3. Objetivos 


\subsection{Objetivo geral}

Avaliar em pacientes submetidas à esterilização tubária por histeroscopia se o uso de diazepam previamente ao procedimento facilita sua inserção ou não, por meio da avaliação do médico insertor em variável fácil, difícil ou se houve falha na colocação dos dispositivos.

\subsection{Objetivos secundários}

Avaliar o efeito do uso do diazepam em pacientes submetidas à esterilização tubária por histeroscopia:

1. Na dor referida pela paciente imediatamente após a inserção;

2. No tempo de inserção. 
4. Casuistica e Métodos 


\subsection{Considerações éticas}

O projeto foi aprovado pelo Comitê de Ética em Pesquisa do Hospital das Clínicas da Faculdade de Medicina de Ribeirão Preto da Universidade de São Paulo (HCFMRP-USP), Processo no 50894915.00000 .5440 (Anexo A).

As pacientes foram convidadas a participar do estudo e devidamente esclarecidas sobre os objetivos e os procedimentos a serem realizados, sendo incluídas as que aceitaram participar da pesquisa e assinaram o Termo de Consentimento Livre e Esclarecido (TCLE) (Anexo B).

\subsection{Tipo de estudo e local de desenvolvimento}

Estudo clínico randomizado, controlado e duplo-cego, conduzido no Centro de Endoscopia do HCFMRP-USP, pelo Setor de Endoscopia Ginecológica.

\subsection{Caracterização da amostra}

As voluntárias que desejaram o método foram encaminhadas ao ambulatório de Cirurgia Ginecológica (ACGC) do HCFMRP-USP e, depois de verificados os critérios de elegibilidade, foram alocadas, de forma consecutiva, no estudo, totalizando 82 mulheres randomizadas em dois grupos. Para o cálculo amostral foram utilizados os seguintes parâmetros: no grupo que não fez uso do diazepam, $70 \%$ dos procedimentos foram considerados fáceis para inserção, e no grupo que recebeu o diazepam $90 \%$ dos procedimentos foram considerados fáceis para inserção, com nível de significância de $5 \%$ e poder de $80 \%$. As estimativas das proporções foram baseadas na mínima diferença clinicamente relevante pelo pesquisador. O cálculo foi realizado no programa SAS versão 9.3 , considerando o procedimento PROC POWER.

Os seguintes parâmetros foram avaliados no dia da alocação: idade, índice de massa corporal, paridade e tipo de parto prévio, cirurgias pélvicas e escolaridade. Após três meses do procedimento, as pacientes foram avaliadas quanto às queixas e confirmação da posição dos seus dispositivos. 


\subsection{Grupo de intervenção}

Quarenta e três mulheres foram recrutadas, depois de avaliadas no Ambulatório de Anticoncepção e liberadas para tal procedimento, tendo cumprido todos os critérios da Lei 9.263 (Lei Sobre Planejamento Familiar), de 1996 (art. 226 da Constituição Federal).

\subsection{Grupo controle}

Trinta e nove mulheres foram recrutadas para o grupo controle (placebo), depois de avaliadas no Ambulatório de Anticoncepção e liberadas para tal procedimento tendo cumprido todos os critérios da Lei 9.263 (Lei Sobre Planejamento Familiar), de 1996 (art. 226 da Constituição Federal).

\subsection{Critérios de exclusão}

- Mulheres com reação alérgica ao componente do níquel presente nos dispositivos;

- Mulheres grávidas ou no período puerperal imediato;

- Uso crônico de medicações que pudessem interferir no limiar de dor (antiinflamatórios esteroidais ou não-esteroidais, antidepressivos e anticonvulsivantes);

- Malformação uterina que impossibilitasse a inserção dos microdispositivos;

- Laqueadura ou cirurgia tubária prévia uni ou bilateral;

- Presença de sinais e/ou sintomas de infecção vaginal/cervical. 


\subsection{Procedimentos}

Grupo intervenção: composto por 43 voluntárias, que receberam um comprimido de $10 \mathrm{mg}$ de diazepam trinta minutos antes do início do procedimento de inserção dos dispositivos.

Grupo controle: formado por 39 voluntárias, que receberam um comprimido sem substância ativa (placebo) trinta minutos antes do início do procedimento.

As pacientes de ambos os grupos receberam AINEs previamente ao início do procedimento para efeito de analgesia, sendo escolhido o diclofenaco $50 \mathrm{mg}$ via oral devido a sua disponibilidade no serviço. Foi realizado teste de gravidez urinário antes da tomada das medicações em todas as pacientes conforme protocolo do serviço. A paciente entrava na sala do exame após trinta minutos da tomada dos comprimidos e após adequadamente posicionada em posição ginecológica, um histeroscópio com ótica de 30 graus, $2,9 \mathrm{~mm}$ e canal de trabalho de $5 \mathrm{Fr}$ (bettocchi, Karl Storz) era introduzido para vaginoscopia. Assim que iniciava a vaginoscopia o cronômetro fixado em sala era acionado, sendo desligado após a retirada do histeroscópio da vagina. Não foi utilizado nenhum tipo de anestesia, apenas analgesia, conforme citado anteriormente.

Todo o procedimento de histeroscopia foi realizado seguindo as etapas necessárias igualmente entre os dois grupos, seguindo o protocolo indicado pelo fabricante e estabelecido em nosso serviço, sempre pelo mesmo pesquisador médico (ACTZ), sendo orientado que evitasse conversar com a paciente antes, durante ou após o procedimento. Apenas uma profissional capacitada e treinada para este procedimento participou deste projeto na etapa da colocação do dispositivo (ACTZ). A tentativa de colocação do dispositivo seguia a ordem de primeiro no óstio esquerdo e depois no direito.

O procedimento de inserção dos dispositivos pelo profissional foi avaliado em fácil ou difícil. Foram consideradas fáceis as inserções em que não houve nenhuma resistência na progressão dos dispositivos; e difícil quando houve resistência na sua progressão, mas com sucesso na colocação. Durante o estudo houve casos em que o dispositivo não progrediu pelos óstios tubários, sendo classificado como falha na colocação do dispositivo. 
Após três meses do procedimento, as pacientes retornaram para avaliação das queixas e do posicionamento dos dispositivos por meio de exame de imagem (ultrassom e histerossalpingografia) e confirmação do sucesso do procedimento se obervada obstrução tubária bilateral, conforme protocolo do serviço. Todas as pacientes foram orientadas a manter o uso de seu anticoncepcional até a confirmação com os exames de imagem.

\subsection{Acompanhamento de sujeitos}

As mulheres foram alocadas aleatoriamente por blocos para dois grupos de intervenção por programa de computador na proporção de 1:1 por randomização por blocos de seis pacientes. Os grupos randomizados foram armazenados em envelopes lacrados por um dos investigadores e somente abertos pelo investigador responsável no momento da alocação das pacientes. O médico que realizou o procedimento não teve qualquer conhecimento do processo de randomização e da tomada da medicação que foi realizado por outros pesquisadores (JCRS e MGR respectivamente).

\subsection{Interrupção do estudo}

Durante a coleta de dados do estudo, o dispositivo utilizado para a esterilização tubária foi suspenso por tempo indeterminado pela ANVISA, o que fez interromper o estudo e publicar os dados obtidos, já que o número de pacientes recrutadas era suficiente para se obterem resultados reprodutíveis.

\subsection{Avaliação da dor}

Foi realizada pela escala visual analógica (EVA) e escala de faces da International Association for the Study of Pain (IASP). A EVA mede $100 \mathrm{~mm}$, sendo que o marco inicial (0) significa ausência de dor e o final da escala (100) a pior dor possível que a mulher pudesse imaginar. A mesma escala também foi analisada de forma qualitativa (0 a $30 \mathrm{~mm}$ : dor leve, 31 a $69 \mathrm{~mm}$ : dor moderada e 70 a $100 \mathrm{~mm}$ : 
dor severa). Assim como a EVA, a escala de faces (Figura 1) pode ser avaliada de forma qualitativa (0 e 2: dor leve; 4 e 6: dor moderada; 8 e 10: dor grave). Imediatamente após o término do procedimento, todas as pacientes eram encaminhadas à sala de recuperação e recebiam um questionário com as duas escalas, EVA E IASP, para responderem sobre a sensação da dor durante o procedimento (Anexo C).

Figura 1: Escala de faces da International Association for the Study of Pain

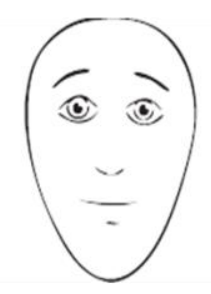

0

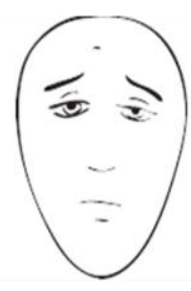

2

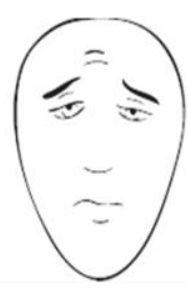

4

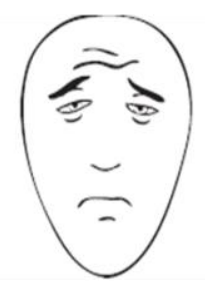

6

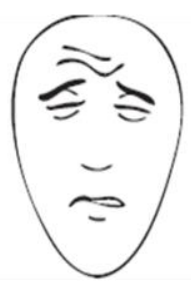

8

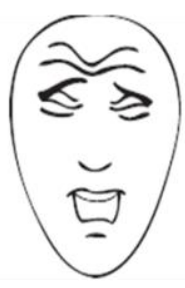

10

\subsection{Análise estatística}

Para as variáveis qualitativas, foi aplicado o teste de Qui-Quadrado, para variáveis quantitativas de distribuição normal, o teste $t$ de Student e para aquelas que não apresentassem distribuição normal o teste de Mann-Whitney. Para concordância intraobservador aplicou-se o Kappa. Para estes cálculos, utilizou-se o software SAS® 9.3 (SAS Institute, Inc., North Carolina State University, NC, USA). O nível de significância adotado foi de $5 \%$. 
5. Resultados 
Foram recrutadas 92 pacientes, sendo oito excluídas do estudo por uso de medicações crônicas que poderiam interferir no limiar da dor e, portanto, na sua avaliação; e duas por falha no disparo do dispositivo. As 82 pacientes foram divididas em dois grupos: um grupo com 43 mulheres que receberam a medicação com princípio ativo e outro com 39 mulheres que receberam a medicação sem substância ativa (placebo). Para cada grupo foram comparados: idade, número de gestações, índice de massa corporal (IMC), cirurgias pélvicas, incluindo cesáreas, e escolaridade. Após três meses do procedimento, as pacientes que retornaram no ambulatório foram avaliadas quanto a queixas e confirmação da posição dos dispositivos.

Para idade e IMC foi realizado o teste estatístico t Student, observando-se que a média entre o grupo que recebeu diazepam foi de 34,3 anos, enquanto que o grupo que recebeu placebo foi de 35 anos. Para o IMC, a média foi de 33,87 no grupo diazepam e 35,37 no grupo placebo, sendo que nenhuma das variáveis comparadas apresentou diferença estatística entre os grupos com $p>0,05$ (Tabela 1). Em relação às variáveis qualitativas, as análises realizadas com o teste QuiQuadrado sobre o número de gestações mostrou que a maioria das pacientes de ambos os grupos tiveram três ou mais gestações; e quanto à escolaridade, a maioria das pacientes possuía ensino fundamental (Tabela 1). Já nas cirurgias pélvicas, o grupo placebo apresentou maior número de pacientes com cirurgias e de cesáreas em relação ao grupo de estudo; porém, mesmo assim, na avaliação das três variáveis apresentadas acima, não se observou diferença estatística $(p>0,05)$ (Tabela 1).

A facilidade na inserção dos dispositivos do lado esquerdo e direito das tubas uterinas foi comparada entre os dois grupos pelo teste Qui-Quadrado e dividida em três categorias: 0 para fácil colocação, 1 para difícil colocação e, portanto, com resistência, e 2 para aquelas em que houve falha na colocação. Também foi avaliada a concordância entre os dois lados das tubas e a facilidade da inserção dos dispositivos por meio do Kappa, no intuito de excluir o viés de a mesma paciente ter avaliações diferentes entre os dois lados. A maioria das pacientes teve a inserção do dispositivo classificada como fácil, com diferença estatística, quando se compararou o lado esquerdo com o direito. O grupo do diazepam no óstio direito apresentou 
maior facilidade na inserção dos dispositivos quando comparado ao grupo placebo do mesmo lado ( $p=0.0464$ ) (Tabela 2). Analisando a concordância pelo Kappa, em ambos os grupos a avaliação de maior frequência, tanto no óstio esquerdo como no direito foi a de fácil colocação, correspondendo a mais de $70 \%$ das avaliações, obtendo-se concordância moderada (Tabela 3).

Em relação à dor durante o procedimento, as pacientes foram avaliadas por duas escalas. Pela IASP (variável qualitativa), realizada por meio do teste QuiQuadrado e dividida em três categorias considerando 0 dor leve, 1 dor moderada e 2 dor severa. A dor moderada foi relatada com maior frequência nos dois grupos, sendo $41,86 \%$ no grupo diazepam e $43,59 \%$ no grupo placebo, respectivamente, não havendo diferença estatística entre eles $(p>0,05)$. Pela EVA, também dividida em três categorias, em que 0 dor leve (0 a $30 \mathrm{~mm}), 1$ dor moderada (31 a $69 \mathrm{~mm}$ ) e 2 dor severa (70 a $100 \mathrm{~mm}$ ), a análise quantitativa pelo teste t Student mostrou que a média das pacientes classificou a dor como moderada sem diferença estatística $(p>0,05)$ (Tabela 4).

Quanto à duração do procedimento, avaliada entre o início da vaginoscopia e o término da mesma, a média de tempo calculada pelo t Student foi de 5,56 minutos no grupo placebo e 5,31 minutos no grupo diazepam, demonstrando não haver diferença estatística entre os grupos $(p>0,05)$ (Tabela 4$)$.

Após três meses, das 82 mulheres que realizaram o procedimento, 60 retornaram ao ambulatório para avaliação quanto às suas queixas. Essa avaliação foi realizada pelo teste Qui-Quadrado que comparou os dois grupos quanto às principais queixas. A maioria das pacientes em ambos os grupos não reportou sintomas na consulta de avaliação pós-procedimento e por isso não houve significância estatística entre os grupos $(p>0,05)$ (Tabela 5). Ainda, dessas 60 pacientes, 51 realizaram exames de ultrassom (US) 3D e histerossalpingografia (HSG), considerada padrão ouro para confirmação da posição dos dispositivos. Esses dados foram comparados por meio do Kappa para elucidar se haveria concordância entre o padrão ouro e o US 3D. Houve fraca concordância entre os grupos (Kappa -0.0615) no óstio esquerdo e fraca concordância (Kappa -0.0285) no óstio direito (Tabelas 6 e 7). 
Durante o exame de HSG, houve passagem do contraste em três pacientes e, portanto, falha do método, sendo duas no lado esquerdo e uma no lado direito e um caso de perfuração da cavidade abdominal no lado esquerdo, suspeitada pelos sintomas da paciente e confirmada pelo Raio-X e US 3D.

Tabela 1 - Comparação das variáveis demográficas entre os dois grupos

\begin{tabular}{lcccc}
\hline \multicolumn{1}{c}{ Medicação } & Grupo Diazepam & Grupo Placebo & P value & DP \\
\hline Idade & 34.37 & 35.05 & 0.5645 & $5.28-5.34$ \\
IMC (Kg/m2) & 33.87 & 35.37 & 0.4181 & $7.47-9.06$ \\
Escolaridade & $48.84 \%$ & $58.97 \%$ & 0.4190 & \\
(Ensino Fundamental) & & & & \\
Escolaridade & $39.53 \%$ & $38.46 \%$ & 0.4190 & \\
$\begin{array}{l}\text { (Ensino Médio) } \\
\text { Escolaridade }\end{array}$ & & & & \\
(Ensino Superior) & $9.30 \%$ & $2.56 \%$ & 0.4190 & \\
$\begin{array}{l}\text { Paridade } \\
\text { (Três ou mais gestações) }\end{array}$ & $58.14 \%$ & $56.41 \%$ & 0.8744 & \\
Cirurgias Pélvicas & $48.83 \%$ & $66.67 \%$ & 0.1093 & \\
\hline
\end{tabular}

Tabela 2 - Comparação das inserções de cada óstio entre os dois grupos

\begin{tabular}{lccc}
\hline \multicolumn{1}{c}{ Medicação } & Grupo Diazepam & Grupo Placebo & $\boldsymbol{P}$ value \\
\hline Fácil Inserção Óstio Esquerdo & $83.72 \%$ & $84.62 \%$ & 0.7273 \\
Fácil Inserção Óstio Direito & $86.05 \%$ & $64.10 \%$ & 0.0464 \\
Difícil Inserção Óstio Esquerdo & $4.65 \%$ & $7.69 \%$ & 0.7273 \\
Difícil Inserção Óstio Direito & $4.65 \%$ & $20.51 \%$ & 0.0464 \\
Falha na Inserção Óstio Esquerdo & $11.63 \%$ & $7.69 \%$ & 0.7273 \\
Falha na Inserção Óstio Direito & $9.30 \%$ & $15.38 \%$ & 0.0464 \\
\hline
\end{tabular}


Tabela 3 - Concordância do resultado da inserção em cada óstio tubário

\begin{tabular}{lcccc}
\hline Óstio Direito/Óstio Esquerdo & Fácil & Difícil & Falha na progressão & Kappa \\
\hline Fácil & $71.95 \%$ & $9.76 \%$ & $2.44 \%$ & 0.6019 \\
Difícil & $2.44 \%$ & $2.44 \%$ & $1.22 \%$ & \\
Falha na progressão & $1.22 \%$ & $0 \%$ & $8.54 \%$ & \\
\hline
\end{tabular}

Tabela 4 - Comparação da dor e duração do procedimento entre os dois grupos

\begin{tabular}{lcccc}
\hline \multicolumn{1}{c}{ Medicação } & Grupo Diazepam & Grupo Placebo & $\boldsymbol{P}$ value & DP \\
\hline Dor Leve (escala de faces) & $34.88 \%$ & $30.77 \%$ & 0.9198 & \\
Dor Moderada (escala de faces) & $41.86 \%$ & $43.59 \%$ & 0.9198 & \\
Dor Severa (escala de faces) & $23.26 \%$ & $25.67 \%$ & 0.9198 & \\
Avaliação da Dor (EVA) & 43.74 & 42.82 & 0.8764 & $26.09-27.51$ \\
Tempo (minutos) & 5.31 & 5.56 & 0.7079 & $2.87-3.27$ \\
\hline
\end{tabular}

Tabela 5 - Comparação das queixas das pacientes entre os dois grupos após três meses do procedimento

\begin{tabular}{lccc}
\hline \multicolumn{1}{c}{ Queixas } & Grupo Diazepam & Grupo placebo & $\boldsymbol{P}$ Value \\
\hline Sem sintomas & $75.00 \%$ & $89.29 \%$ & 0.4291 \\
Sangramento irregular/volumoso & $9.38 \%$ & $7.14 \%$ & \\
Dor pélvica & $12.50 \%$ & $3.57 \%$ & \\
Corrimento & $3.13 \%$ & $0.0 \%$ & \\
\hline
\end{tabular}


Tabela 6 - Concordância entre US 3D e Histerossalpingografia no óstio esquerdo após três meses do procedimento

\begin{tabular}{lccc}
\hline Padrão-Ouro/US 3D lado esquerdo & Cotte negativo & Cotte positivo & Kappa \\
\hline Ideal & $62.75 \%$ & $3.92 \%$ & -0.0615 \\
Distal & $25.49 \%$ & $0.00 \%$ & \\
Muito Distal & $7.84 \%$ & $0.00 \%$ & \\
\hline
\end{tabular}

Tabela 7 - Concordância entre US 3D e Histerosssalpingografia no óstio direito após três meses do procedimento

\begin{tabular}{lccc}
\hline Padrão Ouro/US 3D lado direito & Cotte negativo & Cotte positivo & Kappa \\
\hline Ideal & $50.98 \%$ & $1.96 \%$ & -0.0285 \\
Distal & $29.41 \%$ & $0.00 \%$ & \\
Muito Distal & $17.65 \%$ & $0.00 \%$ & \\
\hline
\end{tabular}


6. Discussão 
Vários fatores são apontados para predizer a taxa de sucesso na colocação dos dispositivos tubários, sendo um deles o uso de medicações previamente ao procedimento, como os AINEs, que parecem facilitar sua colocação através da diminuição do vasoespasmo tubário (10). Em quatro estudos esse efeito foi investigado $(10,28-30)$. Dentre eles, três mostraram que o uso de AINEs antes do procedimento reduz significativamente 0 risco de falha na colocação dos dispositivos. (OR $0.44 ; 95 \% \mathrm{Cl}, 0.21-0.93$, e OR, 0.17; 95\% Cl, 0.03-0.89), respectivamente $(28,29)$, enquanto que um deles não demonstrou diferença estatística (10). Outros quatro estudos avaliaram o efeito de diferentes procedimentos como anestesia geral, sedação endovenosa, raquianestesia, bloqueio paracervical ou nenhuma intervenção; e concluíram não haver diferença estatística no risco de falha com o uso desses diferentes analgésicos (31-34).

O único estudo encontrado na literatura associando a diminuição do vasoespasmo tubário com diazepam foi realizado em pacientes com infertilidade e que foram submetidas ao procedimento de HSG para elucidação diagnóstica da infertilidade. Nesse estudo, as pacientes receberam diazepam associado a outras medicações antes do procedimento, evidenciando em $82 \%$ dos casos patência bilateral no exame e naquelas não pérvias que foram para laparoscopia, 93\% confirmaram o diagnóstico de oclusão tubária, demonstrando eficácia das medicações administradas quanto à patência no exame (35).

No presente estudo, a facilidade na colocação dos dispositivos foi maior no óstio direito no grupo que recebeu o diazepam, em relação ao grupo placebo. Uma explicação para tal resultado é a possibilidade de que a melhor visualização do óstio direito por motivos anatômicos poderia facilitar tal inserção. Panel e Grosdemouge (10) apontaram os fatores que poderiam influenciar a colocação dos dispositivos tubários e o único fator que apresentou diferença estatística em uma casuística de 459 pacientes foi a boa visualização dos óstios tubários durante a tentativa de colocação dos dispositivos.

Outra hipótese plausível seria a do mecanismo de relaxamento tubário, apesar de não haver estudos associando o efeito dos BZNs sobre a tuba uterina e os receptores $\alpha$ e $\beta$. Sabe-se que nas tubas uterinas, os $\alpha$-receptores geralmente são estimulantes, enquanto que os $\beta$-receptores são inibitórios. Os receptores $\beta$ no 
trato genital são categorizados em $\beta 1$ e $\beta 2$, porque são estimulados mais pela epinefrina do que pela norepinefrina (14). No istmo da tuba uterina humana, os $\beta$ receptores predominam na musculatura circular e a norepinefrina causa relaxamento tubário em todos os estágios do ciclo menstrual, exceto no período ovulatório, quando sob a influência de altos níveis plasmáticos de estradiol, os a-receptores predominam brevemente estimulando a contratilidade tubária (36). Inversamente, o efeito do aumento nos níveis plasmáticos de progesterona altera a resposta à norepinefrina induzindo um relaxamento istmico acentuado, observado in vitro vários dias após a ovulação (37). Zupkó et al (26) avaliaram o efeito de certos BZNs como tocolíticos, em modelos de rato in vivo no pós-parto, sendo um deles o diazepam. Os autores concluiram que os BZNs exercem ação inibitória sobre os a- receptores, causando efeito de relaxamento na musculatura uterina na avaliação experimental, promovendo efeito tocolítico, apesar de seu possível efeito colateral sobre o binômio mãe e feto.

Quanto ao tempo e dose da tomada do diazepam, escolheu-se o intervalo de 30 minutos e dose de $10 \mathrm{mg}$ visando menor influência dos efeitos colaterais como sedação e alteração da memória durante o procedimento que poderiam confundir a avaliação da inserção do dispositivo e os resultados do estudo. Friedman et al. (38) desenvolveram um estudo sobre a farmacocinética e farmacodinâmica de doses orais de diazepam (2 mg, $5 \mathrm{mg}$ e $10 \mathrm{mg}$ ) comparadas com placebo. As concentrações plasmáticas e seus efeitos foram avaliados entre 15, 30 e 45 minutos, 1 hora até 12 horas. Quando compararam o efeito de sedação após $5 \mathrm{mg}$ de diazepam, observaram diminuição significativa do nível de consciência entre 1 e 2 horas após a administração da dose e de 45 minutos a 3 horas após a dose de 10 mg de diazepam e as pontuações no teste de memória de Randt foram reduzidas em 1 hora após o teste com a dose de $5 \mathrm{mg}$ de diazepam e 45 minutos após a dose de $10 \mathrm{mg}$. Assim, foi possível utilizar uma dose padrão preconizada e um intervalo de tempo aparentemente adequado para minimizar o viés dos efeitos colaterais de um BZN.

Já quando comparado o índice de falha na colocação dos dispositivos, este estudo obteve taxa de falha em torno de $15 \%$ no lado direito e $11 \%$ no lado esquerdo, o que fez com que tais pacientes tivessem que repetir o procedimento 
para uma segunda tentativa ou realizassem laparoscopia para salpingectomia. Em metanálise publicada em 2015, la Chapelle et al. (2) compilaram 31 estudos realizados com $E s s u r e \AA$, em que a taxa de falha na primeira tentativa de colocação variou entre $2 \%$ e $19 \%$, mostrando que o presente estudo obteve variação semelhante aos estudos internacionais.

Outro ponto a ser observado é a média do tempo de colocação. Em estudo italiano realizado com 1.913 mulheres, Franchini et al. (8) obtiveram média de 7,8 minutos de duração em procedimento de esterilização tubária, enquanto que a presente amostra apresentou média de 5,31 minutos no grupo diazepam e 5,56 minutos no placebo obtendo valores de média um pouco menores quando comparados os dois estudos. Já Panel e Grosdemouge (10) relataram média de 11 minutos na duração do procedimento.

Quanto à idade, este estudo obteve média de 34.3 anos para o grupo diazepam e 35 anos para o grupo placebo. A maioria das pacientes foi classificada com obesidade e haviam tido pelo menos três gestações. Comparando com o estudo de Franchini et al. (8), cuja a média de idade foi de 39.5 anos, enquanto que a paridade foi de 1,8 gestações e a maioria das pacientes tinham IMC normal $(23,4$ kg/m2). Já no estudo de Panel e Grosdemouge (10), a média de idade foi de 42 anos e a paridade de 2,45 gestações e, portanto, quando comparados os três estudos, o presente estudo obteve médias de idade menores e maiores paridades, o que pode refletir no nível socioeconômico dos países, visto que a maioria das pacientes recrutadas possuía apenas ensino fundamental.

Em relação aos sintomas, a maioria das pacientes deste estudo relatou moderada dor durante o procedimento, porém boa adaptação após os três meses de reavaliação, em que as queixas foram insignificantes em ambos os grupos. No estudo de Franchini et al. (8), a maioria das mulheres submetidas à colocação de Essure $B^{\circ}$ estavam satisfeitas com sua escolha e não relataram nenhum efeito em longo prazo. A dor pós-procedimento foi mínima e de curta duração. Em nove mulheres, nos primeiros 14 meses após a colocação de Essure®, a dor pélvica tornou-se intratável, necessitando remover o dispositivo. O presente estudo não avaliou as pacientes em longo prazo e, portanto, não foi possível compará-los, mas observou-se discrepância entre a dor pós-procedimento, pois o presente estudo 
obteve média de dor de moderada intensidade, que poderia ser explicada pela dificuldade das pacientes em entender o questionário das escalas IASP e EVA, devido o nível de escolaridade.

Avaliando os casos de intercorrências, este estudo apresentou um caso de perfuração, diagnosticado pelos sintomas da paciente e confirmado pelo US 3D e exame de Raio-X, sendo a mesma submetida à laparoscopia para retirada do corpo estranho e salpingectomia bilateral; e em três casos houve falha na inserção do dispositivo, confirmada após três meses pela HSG com Cotte positivo unilateral, sendo essas pacientes submetidas à salpingectomia bilateral por laparoscopia. Comparando com estudos internacionais, Hitzerd et al. (39) relataram 10 casos de perfuração tubária, porém em casuística de 27.346 pacientes, enquanto que Franchini et al. (8) descreveram quatro perfurações em 1.913 colocações, números maiores que os da presente amostra, provavelmente devido ao número de pacientes recrutadas sermaior.

Por fim, o presente estudo procurou avaliar uma medicação preconizada pelo fabricante em bula e que apesar de ter efeitos colaterais em doses maiores, a dose de $10 \mathrm{mg} 30$ minutos antecedendo o procedimento de esterilização tubária histeroscópica não pareceu ter prejudicado as pacientes avaliadas e pareceu haver um efeito benéfico em facilitar a inserção do dispositivo no lado direito das pacientes que a nosso ver pode ter sido pela maior facilidade de colocação desse lado por motivos anatômicos, ou por provável mecanismo de relaxamento tubário induzido pela medicação estudada, podendo haver associação entre BZNs, como o diazepam, e o relaxamento da musculatura lisa tubária, que contém receptores alfa e beta adrenérgicos; sendo sua ação inibitória nos receptores alfa a provável responsável por esse mecanismo. Assim, tais achados poderão servir de ferramenta para novos estudos. 
7. Conclusões 
Após análise dos resultados, concluiu-se que:

a. O uso do diazepam prévio na dose de $10 \mathrm{mg}$, administrado 30 minutos previamente à esterilização tubária histeroscópica, pareceu facilitar a colocação do dispositivo contraceptivo no lado direito, com significância estatística e moderada concordância por meio do Kappa.

b. A maioria das pacientes apresentou dor considerada moderada, tanto pela escala IASP quanto pela EVA, quando comparadas nos dois grupos.

c. O tempo médio de duração entre os dois grupos foi de aproximadamente cinco minutos e 43 segundos.

d. O diazepam na dose de $10 \mathrm{mg}$ parece apresentar efeito benéfico no óstio direito ao facilitar a inserção do dispositivo de esterilização tubária quando utilizado previamente ao procedimento, abrindo espaço para novos estudos a fim de confirmar tal benefício antes de ser administrado de rotina. 


\section{Referências Bibliográficas}

${ }^{1}$ Elaboradas de acordo com as Diretrizes para Apresentação de Dissertações e Teses da USP: Documento Eletrônico e Impresso - Parte IV (Vancouver) 3르 ed. São Paulo: SIBi/USP, 2016. 
1. McMartin K. Hysteroscopic tubal sterilization: na evidence-based analysis. Ont Health Technol Assess Ser. 2013;13(21):1-35.

2. Ia Chapelle CF et al. Effectiveness and feasibility of hysteroscopic sterilization techniques: a systematic review and meta-analysis. Fertil Steril. 2015;103(6):1516-25.e1-3.

3. Loffer FD. What's new in female sterilization? The silicone tubal plug is. Ariz Med. 1982;39(7):442-5.

4. Franchini $M$ et al. Essure permanent birth control, effectiveness and safety: an Italian 11-year survey. J Minim Invasive Gynecol. 2017;24(4):640-5.

5. Fernandez et al. Tubal sterilization: pregnancy rates after hysteroscopic versus laparoscopic sterilization in France, 2006-2010. Eur J Obstet Gynecol Reprod Biol. 2014;180:133-7.

6. Walter JR et al. Hysteroscopic sterilization with essure: summary of the u.s. food and drug administration actions and policy implications for postmarketing surveillance. Obstet Gynecol. 2017;129(1):10-19.

7. Panel P, Grosdemouge I. Predictive factors of Essure implant placement failure: prospective, multicenter study of 495 patients. Fertil Steril. 2010;93(1):29-34.

8. Barr ML. The human nervous system. An anatomical viewpoint. Hagerstown: Harper \& Row, 1974, p. 343-4.

9. Owman Ch, Rosengren E, Sjöberg N. Adrenergic innervation of the human female reproductive organs: a histochemical and chemical investigation. Obstet Gynecol. 1967;30(6):763-73.

10. Jansen R. Endocrine response in the fallopian tube department of obstetrics and gynaecology. Endoc Ver. 1984;5(4):525-51.

11. Pauerstein CJ, Eddy CA. The role of the oviduct in reproduction; our knowledge and our ignorance. J Reprod Fertil. 1979;55(1):223-9.

12. Preskorn SH. A way of conceptualizing benzodiazepines to guide clinical use. J Psychiatr Pract. 2015;21(6):436-41.

13. Charney DS, Mihic SJ, Harris RA. Hypnotics and sedatives. In: Brunton LL ET AL. (eds.). The pharmacological basis of therapeutics, 11th ed, New York: McGraw-Hill Medical Publishing; 2006, pp.402-12.

14. Mandrioli R, Mercolini L, Raggi MA. Benzodiazepine metabolism: an analytical perspective. Curr Drug Metab. 2008;9(8):827-44. 
15. Hong SJ, Damron DS, Murray PA. Benzodiazepines differentially inhibit phenylephrine-induced calcium oscillations in pulmonary artery smooth muscle cells. Anesthesiol. 1998;88(3):792-9.

16. Waugh DJJ et al. Binding, partial agonism, and potentiation of a1-adrenergic receptor function by benzodiazepines: a potential site of allosteric modulation. $J$ Pharmacol Exp Ther. 1999;291(3):1164-71.

17. Landesman $\mathrm{R}$, Wilson $\mathrm{KH}$. Relaxant effect of diazepam on uterine muscle. Obstet Gynecol. 1965;26(4):552-6.

18. Ronca-Testoni $\mathrm{S}$ et al. Benzodiazepine binding sites in human myometrium. Int $\mathrm{J}$ Tissue React. 1984;6(5):437-41.

19. Zupkó I et al. Alpha-adrenergic blockade: a possible mechanism of tocolytic action of certain benzodiazepines in a postpartum rat model in vivo. Life Sci. 2003;72(10):1093-102.

20. Chern B, Siow A. Initial Asian experience in hysteroscopic sterilisation using the Essure permanent birth control device. BJOG. 2005;112(9):1322-7.

21. Nichols $M$ et al. A comparative study of hysteroscopic sterilization performed inoffice versus a hospital operating room. J Minim Invasive Gynecol. 2006;13(5):447-50.

22. Cooper JM et al. Microinsert nonincisional hysteroscopic sterilization. Selective Tubal Occlusion Procedure 2000 Investigators Group. Obstet Gynecol. 2003;102(1):59-67.

23. Lopes $P$ et al. Hysteroscopic tubal sterilization with essure intratubal devices: a case-control prospective with inert local anesthesia or without anesthesia. Eur $\mathrm{J}$ Obstet Gynecol Reprod Biol. 2008;138(2):199-203.

24. Levie M, Chudnoff SG. A comparison of novice and experienced physicians performing hysteroscopic sterilization: an analysis of an FDA-mandated trial. Fertil Steril. 2011;96(3):643-8.e1.

25. Leyser-Whalen $O$ et al. Tubal risk markers for failure to place transcervical sterilization coils. Contraception. 2012;85(4):384-8.

26. Shavell $\mathrm{VI}$ et al. Placement of a permanent birth control device at a university medical center. J Reprod Med 2009;54(4):218-22.

27. Sienkiewicz R, Rózewicki S. Evaluation of combined application of diazepam, fenoterol and metamizole in prevention of uterine-tubal spasm during the performance of hysterosalpingography. Ginekol Pol. 1992;63(10):512-4. 
28. Hicks CL et al. The Faces Pain Scale - Revised: Toward a common metric in pediatric pain measurement. Pain. 2001;93(2):173-83.

29. Hitzerd $\mathrm{E}$ et al. Twelve-year retrospective review of unintended pregnancies after Essure sterilization in the Netherlands. Fertil Steril. 2016;105(4):932-7.

30. Friedman $\mathrm{H}$ et al. Pharmacokinetics and pharmacodynamics of oral diazepam: effect of dose, plasma concentration, and time. Clin Pharmacol Ther. 1992;52(2):139-50.

31. Sinha $D$ et al. The feasibility, success and patient satisfaction associated with outpatient hysteroscopic sterilisation. BJOG. 2007;114(6):676-83.

32. Lett CD, Thiel JA. The effect of menstrual phase and hormonal contraception on successful bilateral placement of the Essure micro-insert tubal coil. Gynecol Surg. 2009;6(3):219-22.

33. Varo B et al. Essure hysteroscopic tubal sterilization: our first clinical experience. Rev Iberoam Fertil Reprod Humana 2010;27(2):125-9.

34. Coupland RE. Catecholamines. In: Barrington EJW (Ed.) Hormones and Evolution. New York: Academic Press, 1979, p. 309.

35. Batra $S$ et al. Female sex steroid concentrations in the ampullary and isthmic regions of the human Fallopian tube and their relationship to plasma concentrations during the menstrual cycle. Am J Obstet Gynecol. 1980;136(8):986-91.

36. Kubo K, Kawano J, Ishii S 1970 Some observations on the autonomic innervation of the human oviduct. Int J Fertil 15:30

37. Wittenborn JR. Effects of benzodiazepines on psychomotor performance. $\mathrm{Br} \mathrm{J}$ Clin Pharmacol. 1979;7():61s-7s.

38. Moawad AH. Effects of progesterone on the adrenergic mechanisms of the genital tract. Ann NY Acad Sci. 1977;286:287-303.

39. Owman $\mathrm{CH}$ et al. Autonomic nerves and related amine receptors mediating motor activity in the oviduct of monkey and man. Histochemical, chemical and pharmacological study. In: Harper MJK et al. (eds.). (Proceedings of a Meeting of the World Health Organization (WHO) Task Force on Methods for a regulation of Ovum transportation. San Antonio, Texas, June 23-27, 1975). Copenhagen, Denmark, Scriptor, 1976. 256-75. 
9. Anexos 


\section{ANEXO A - COMPROVANTE dE APROVAÇÃo dO COMITÊ DE ÉTICA}

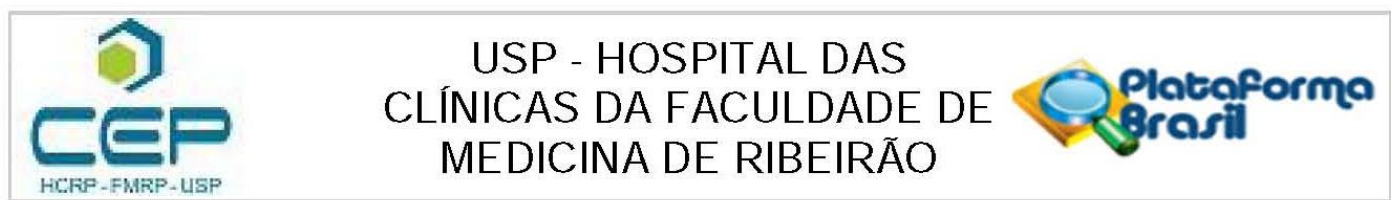

\section{PARECER CONSUBSTANCIADO DO CEP}

\section{DADOS DA EMENDA}

Título da Pesquisa: Efeito do diazepam em facilitar a colocaçāo dos dispositivos durante procedimento de esterilização tubaria por histeroscopia: estudo clínico randomizado e controlado

Pesquisador: MARINA GONZALEZ RIBAS

Área Temática:

Versão: 2

CAAE: 50894915.0 .0000 .5440

Instituição Proponente: Hospital das Clínicas da Faculdade de Medicina de Ribeirão Preto da USP -

Patrocinador Principal: Financiamento Proprio

\section{DADOS DO PARECER}

Número do Parecer: 3.117 .932

Apresentação do Projeto:

Trata-se de emenda ao projeto de pesquisa solicitando adequação no título do estudo.

Resumo:

Diante da falta de informaçōes na literatura sobre o uso de diazepam previo ao procedimento de laqueadura tubária por histeroscopia, o presente estudo visa avaliar esse efeito permitindo demonstrar se ele é benéfico, o que resultaria em maior facilidade na inserção dos micro-dispositivos tubários e portanto diminuindo o tempo do procedimento e até mesmo a dor entre as pacientes que utilizarem a medicação. Em vários estudos sobre

esterilização tubária por histeroscopia as pacientes receberam medicação previa ao procedimento no geral uma combinação de anti-inflamatórios não esteroidais (AINEs) com diazepam. Em três deles esse efeito foi investigado. Dentre eles, dois estudos mostraram que o uso de AINEs antes do procedimento reduz significantemente o risco de falha na colocação dos dispositivos. (OR $0.44 ; 95 \% \mathrm{Cl}, 0.21-0.93$, e OR, 0.17; $95 \% \mathrm{Cl}, 0.03-0.89)$

respectivamente, enquanto que o terceiro estudo não achou diferença estatística. Neste último, o grupo que não recebeu AINEs pré-procedimento foi pequeno. (OR, 1.71; $95 \% \mathrm{Cl}, 0.22-13.35)$. Outros quatros estudos avaliaram o efeito de diferentes procedimentos como anestesia geral, sedação endovenosa, raquianestesia, bloqueio paracervical ou nenhuma intervenção e concluíram

Endereço: CAMPUS UNIVERSITÁRIO

Bairro: MONTE ALEGRE CEP: $14.048-900$

UF: SP Municipio: RIBEIRAO PRETO

Telefone: (16)3602-2228 $\quad$ Fax: (16)3633-1144 E-mail: cep@hcrp.usp.br 


\section{USP - HOSPITAL DAS \\ CLÍNICAS DA FACULDADE DE MEDICINA DE RIBEIRÃO}

Continuação do Parecer: 3.117 .932

não haver diferença estatística no risco de falha com uso

desses diferentes analgésicos.

\section{Objetivo da Pesquisa:}

Objetivo Primário:

Avaliar em pacientes que irão realizar laqueadura tubária por histeroscopia se o uso de diazepam previamente ao procedimento facilita sua inserção ou não, através da avaliação do médico insertor em uma variável dicotômica (fácil ou difícil).

Objetivo Secundario:

Avaliar o efeito do uso de diazepam em pacientes que irão realizar laqueadura tubaria por histeroscopia:1. $\mathrm{Na}$ dor referida pela paciente imediatamente apos a inserção.2. No tempo de inserção.

\section{Avaliação dos Riscos e Benefícios:}

Não se aplica

\section{Comentários e Considerações sobre a Pesquisa:}

O pesquisador solicita a modificação do título do estudo da pós graduanda Marina Gonzalez Ribas conforme sugerido por banca avaliadora dos resultados parciais da Faculdade de Medicina de Ribeirão Preto da Universidade de São Paulo na data de 12/06/2017 de "Efeito do uso de diazepam no relaxamento das tubas uterinas durante procedimento de laqueadura tubária por histeroscopia: estudo clínico randomizado e controlado"para:"Efeito do diazepam em facilitar a colocação dos dispositivos durante procedimento de esterilização tubaria por histeroscopia: estudo clínico randomizado e controlado"visto que o presente estudo não avalia o relaxamento das tubas uterinas e sim se o uso de tal medicação facilita a colocação dos dispositivos.

\section{Considerações sobre os Termos de apresentação obrigatória:}

Documentos da emenda:

- Folhaderostoassinada2.pdf

- Relatorioparcial.docx

- EmendaMudancadeTitulo.docx

- ProjetoDiazepamversao2.docx

- TCLEversao2.docx

Recomendações:

Não há.

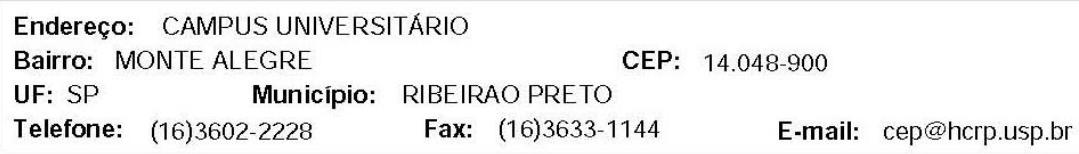




\section{USP - HOSPITAL DAS \\ CLÍNICAS DA FACULDADE DE MEDICINA DE RIBEIRÃO}

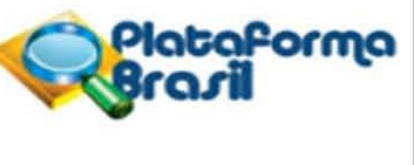

Continuação do Parecer: 3.117 .932

\section{Conclusões ou Pendências e Lista de Inadequações:}

O CEP analisou e aprovou a Emenda referente a alteração do título da pesquisa para "Efeito do diazepam em facilitar a colocação dos dispositivos durante procedimento de esterilização tubária por histeroscopia: estudo clínico randomizado e controlado", bem como o projeto de pesquisa versāo 2 atualizada em 30/08/2018 e o Termo de Consentimento Livre e Esclarecido Versão atualizada em 30/08/2018. O CEP tomou ciencia do Relatório Parcial.

\section{Considerações Finais a critério do CEP:}

Este parecer foi elaborado baseado nos documentos abaixo relacionados:

\begin{tabular}{|c|c|c|c|c|}
\hline Tipo Documento & Arquivo & Postagem & Autor & Situação \\
\hline $\begin{array}{l}\text { Informaçōes Básicas } \\
\text { do Projeto }\end{array}$ & $\begin{array}{l}\text { PB_INFORMAÇŐES_BÁSICAS_103199 } \\
8 \text { E1.pdf }\end{array}$ & $\begin{array}{c}16 / 12 / 2018 \\
07: 40: 37 \\
\end{array}$ & & Aceito \\
\hline Folha de Rosto & Folhaderostoassinada2.pdf & $\begin{array}{c}16 / 12 / 2018 \\
07: 39: 20 \\
\end{array}$ & $\begin{array}{l}\text { MARINA GONZALEZ } \\
\text { RIBAS } \\
\end{array}$ & Aceito \\
\hline Outros & Relatorioparcial.docx & $\begin{array}{c}30 / 08 / 2018 \\
17: 31: 30 \\
\end{array}$ & $\begin{array}{l}\text { MARINA GONZALEZ } \\
\text { RIBAS }\end{array}$ & Aceito \\
\hline Outros & EmendaMudancadeTitulo.docx & $\begin{array}{c}30 / 08 / 2018 \\
17: 30: 29\end{array}$ & $\begin{array}{l}\text { MARINA GONZALEZ } \\
\text { RIBAS }\end{array}$ & Aceito \\
\hline $\begin{array}{l}\text { Projeto Detalhado / } \\
\text { Brochura } \\
\text { Investigador }\end{array}$ & ProjetoDiazepamversao2.docx & $\begin{array}{c}30 / 08 / 2018 \\
17: 28: 29\end{array}$ & $\begin{array}{l}\text { MARINA GONZALEZ } \\
\text { RIBAS }\end{array}$ & Aceito \\
\hline $\begin{array}{l}\text { TCLE / Termos de } \\
\text { Assentimento / } \\
\text { Justificativa de } \\
\text { Ausencia }\end{array}$ & TCLEversao2.docx & $\begin{array}{c}30 / 08 / 2018 \\
17: 27: 31\end{array}$ & $\begin{array}{l}\text { MARINA GONZALEZ } \\
\text { RIBAS }\end{array}$ & Aceito \\
\hline Outros & OrcamentoAprovadoUPC.PDF & $\begin{array}{c}12 / 11 / 2015 \\
12: 39: 16\end{array}$ & $\begin{array}{l}\text { MARINA GONZALEZ } \\
\text { RIBAS }\end{array}$ & Aceito \\
\hline Outros & AprovacaoDepartamentoG02.jpg & $\begin{array}{c}11 / 11 / 2015 \\
17: 19: 07\end{array}$ & $\begin{array}{l}\text { MARINA GONZALEZ } \\
\text { RIBAS }\end{array}$ & Aceito \\
\hline Outros & AprovacaoDepartamentoG01.jpg & $\begin{array}{c}11 / 11 / 2015 \\
17: 18: 20 \\
\end{array}$ & $\begin{array}{l}\text { MARINA GONZALEZ } \\
\text { RIBAS }\end{array}$ & Aceito \\
\hline
\end{tabular}

\section{Situação do Parecer:}

Aprovado

\section{Necessita Apreciação da CONEP:}

Não

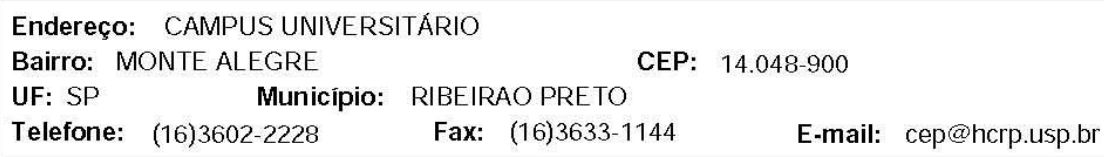




\section{USP - HOSPITAL DAS \\ CLÍNICAS DA FACULDADE DE} MEDICINA DE RIBEIRÃO

Continuação do Parecer: 3.117.932

RIBEIRAO PRETO, 22 de Janeiro de 2019

Assinado por:

MARCIA GUIMARÃES VILLANOVA

(Coordenador(a)) 


\section{ANEXO B - TERMO DE CONSENTIMENTO LIVRE E ESCLARECIDO}

Título: Efeito do diazepam em facilitar a colocação dos dispositivos durante procedimento de esterilização tubária por histeroscopia: estudo clínico randomizado e controlado.

\section{Pesquisadores responsáveis e seus contatos:}

Prof. Dr. Julio Cesar Rosa e Silva e Dra. Marina Gonzalez Ribas

Departamento de Ginecologia e Obstetrícia da Faculdade de Medicina de Ribeirão Preto - USP

Av. Bandeirantes, 3900, Campus Universitário, Monte Alegre, Ribeirão Preto, SP

Tel: (16) 3602-2814 (manhã) e 3963-2791 (tarde)

Celular: (16) 991076016

Prezada senhora,

Você escolheu como método para prevenir contra a gestação a laqueadura tubária por histeroscopia (Essure) que consiste na colocação permanente de pequenas molas dentro das duas trompas por histeroscopia (procedimento realizado pela vagina e colo do útero). Para colocação dessas molas normalmente é realizado 30 minutos antes do inicio do procedimento a tomada de um comprimido de diazepam de $10 \mathrm{mg}$ no intuito de facilitar a colocação e diminuir a dor da paciente. Porém em algumas pacientes esta medicação não tem o efeito esperado. Até o momento, poucos estudos existem para provar que a medicação facilita a colocação das molas e diminui a dor da paciente.

Desta forma, a senhora está sendo convidada a participar da pesquisa "Efeito do diazepam em facilitar a colocação dos dispositivos durante procedimento de esterilização tubária por histeroscopia: estudo clínico randomizado e controlado".

\section{Objetivo da pesquisa}

Esta pesquisa tem como objetivo avaliar se o uso de $10 \mathrm{mg}$ de diazepam via oral 30 minutos antes da colocação permanente de pequenas molas nas duas trompas (laqueadura tubária por histeroscopia) é capaz de facilitar o procedimento e diminuir a dor da paciente.

Após verificarmos que você pode participar da pesquisa, você será convidada a participar da pesquisa. Sua participação nesta pesquisa será avaliar a dor associada à colocação das pequenas molas (Essure) por meio de uma régua (chamada de escala) que mostra se a dor é leve, moderada ou forte. Esta escala será aplicada logo após terminar o procedimento. Depois de 90 dias, você fará um exame de imagem (ultrassom ou histerossalpingografia) e voltará ao ambulatório para checar se as molas estão dentro das trompas e assim finalizando sua participação no estudo. Esse retorno e este exame de imagem após 90 dias da colocação das molas é feita para todas as mulheres, mesmo aquelas que não participam do estudo. Assim que confirmado o correto posicionamento das molas 
você terá alta do ambulatório como acontece com as pacientes que não participarão desse estudo. Os responsáveis por estes ambulatórios estão identificados no inicio do termo juntamente com os telefones de contato.

\section{Grupos de estudo e como serão determinados}

Haverá dois grupos de mulheres no estudo: um grupo receberá o comprimido de $10 \mathrm{mg}$ de diazepam 30 minutos antes do início do procedimento e outro grupo receberá um comprimido sem substância dentro (placebo) também 30 minutos antes do início do procedimento. Antes da tomada do comprimido todas as pacientes realizarão o teste de gravidez urinário conforme orientação do fabricante.

\section{Participação voluntária e manutenção de sigilo}

Você foi encaminhada da rede de saúde ou do ambulatório de anticoncepção do HC para realizar laqueadura tubária por histeroscopia neste hospital. Aqui estamos Ihe convidando a participar desta pesquisa. Caso você aceite, você assinará duas cópias deste termo e uma das cópias ficará com a senhora. Após isto, programaremos o dia do procedimento mesmo que você não queira participar do estudo. No dia da laqueadura tubária por histeroscopia, faremos a colocação das pequenas molas tendo sorteado qual grupo você fará parte (grupo que toma o comprimido de diazepam ou o grupo que toma o comprimido de placebo). Depois da colocação, faremos perguntas para você dizer se sentiu dor ou não e caso tenha sentido, qual a intensidade dela. O tempo entre colocar as molas e terminarmos as perguntas sobre a dor é estimado em 30 minutos.

A sua participação nesta pesquisa é voluntária, tendo a senhora a liberdade de se recusar a participar. Caso aceite participar, seu nome ficará em segredo, não aparecendo em qualquer etapa da análise dos dados assim como nos resultados da pesquisa, de forma a manter seu sigilo e privacidade. Caso concorde em participar, poderá também desistir a qualquer momento e retirar seu consentimento, sem nenhum prejuízo para o seu seguimento no ambulatório.

Para resguardar sua privacidade e anonimato, os materiais e documentos de pesquisa serão armazenados em computadores protegidos por senha e de posse dos pesquisadores deste estudo, com acesso restrito a estes, não sendo divulgado a outras pessoas.

\section{Avaliação de riscos}

Como riscos, consideramos aqueles vindos da colocação das pequenas molas nas trompas, seja para o grupo que tomará o diazepam ou aquele que tomará o placebo, destacando: perfuração das trompas, mau posicionamento das molas, migração das molas para cavidade abdominal, expulsão dos dispositivos, sangramento ou infecção. Caso ocorra, the prestaremos todo atendimento necessário para a solução do problema.

Já os efeitos colaterais mais frequentemente relatados com uso do diazepam são: cansaço, sonolência e relaxamento muscular. Outras reações raras são: depressão, secura na boca, cefaleia (dor de cabeça), enjoo ou vômitos, fala enrolada, euforia (agitação), confusão, vertigem (tontura), manifestações cardiovasculares tais como, bradicardia (coração bater devagar) e hipotensão (pressão baixa).

\section{Avaliação de benefício}


A laqueadura tubária por histeroscopia é um dos métodos mais eficazes do mundo para prevenir gravidez, com taxas de falha semelhante as da laqueadura tubária convencional (via abdominal ou laparoscópica) com falha de 5 em cada 1000 mulheres. No entanto, é pouco usado no Brasil por falta de oferta e por falta de conhecimento sobre o método por parte do médico e das mulheres. Conhecer uma forma de facilitar a realização desse método e diminuir a dor da paciente poderia aumentar o uso deste método pelas mulheres. Os resultados da pesquisa serão divulgados em publicações e eventos científicos, bem como para instituições relacionadas à saúde.

\section{Indenizações e ressarcimentos}

Você receberá auxílio transporte e alimentação para que a vinda para laqueadura tubária por histeroscopia fora do dia que você normalmente viria não lhe cause prejuízo.

Os pesquisadores do presente estudo se responsabilizam por qualquer dano causado decorrente desta pesquisa. Você tem direito à indenização conforme as leis vigentes no país caso ocorra dano decorrente da sua participação nesta pesquisa. $O$ estudo não apresenta seguro.

\section{Se Você Tiver Perguntas Ou Tiver Um Problema}

Se desejar informações adicionais, a senhora poderá contatar os pesquisadores através dos dados acima, ou através do Comitê de Ética em Pesquisa do Hospital das Clínicas da Faculdade de Medicina de Ribeirão Preto USP pelo telefone 3602-2228, com horário de funcionamento de segunda à sexta das $7 \mathrm{~h} 30$ às $17 \mathrm{~h}$. Caso você apresente algum sintoma que lhe cause desconforto, você pode comparecer nos ambulatórios de cirurgia ginecológica do HC de Ribeirão (sempre nas quartas ou sextas-feiras das $12: 30$ as 18:00). Caso seu sintoma apareça fora do dia do ambulatório, você pode ligar para os telefones indicados no inicio deste termo e indicaremos onde você será avaliada. Caso você tenha alguma emergência, você poderá comparecer na Unidade de Emergência do Hospital das Clínicas de Ribeirão Preto (conhecida como Hospital das Clínicas "velho", endereço: Rua Bernardino de Campos, 1.000, Ribeirão Preto) e nossa equipe será contatada. Essa pesquisa foi aprovada pelo Comitê de Ética em Pesquisa que tem a finalidade de proteger eticamente o participante da pesquisa.

Esse termo será assinado pela pesquisadora responsável e por você, em duas vias, sendo que uma via assinada ficará com você. 
$\mathrm{Eu}$, , li este documento (ou ele foi lido para mim) descrevendo os benefícios, os riscos e os procedimentos, para o estudo de pesquisa denominado: "Efeito do diazepam em facilitar a colocação dos dispositivos durante procedimento de esterilização tubária por histeroscopia: estudo clínico randomizado e controlado", e minhas perguntas foram respondidas. Eu ainda não participei de nenhum procedimento do estudo. Eu concordo livremente em participar como voluntária. Eu receberei uma cópia deste documento.

Através da assinatura do meu nome na linha abaixo, eu concordo em participar deste estudo de pesquisa e aceito os riscos.

Nome do Participante

Nome do Pesquisador
Assinatura

Assinatura
Data e horário

Data e horário 


\section{ANEXO C - FICHA CLÍNICA}

Nome:

Registro do HC:

Idade:

Paridade

IMC (kg/m2):

Escolaridade:

Contato (Tel):

Patologias:

Medicações:

Alergias:

Cirurgias prévias:

Usa medicações cronicamente como ansiolíticos, antidepressivos, AINEs ou anticonvulsivantes? Sim Não Qual:

Paciente: Após realizado procedimento, qual sua avaliação em relação à dor pela EVA: $0-30 \mathrm{~mm}$ (dor leve), $31-69 \mathrm{~mm}$ (dor moderada), $70-100 \mathrm{~mm}$ (dor grave)

Paciente: Após realizado procedimento, qual sua avaliação em relação à dor pela Escala de Faces: $0-2$ (dor leve), 4-6 (dor moderada), 8-10 (dor grave)

Avaliador: Inserção dos dispositivos: . 1- Óstio Esquerdo: Fácil Difícil 2- Óstio Direito: Fácil Difícil

Avaliador: Tempo total do procedimento (contagem a partir do início da vaginoscopia em minutos): 